\title{
ERRATUM
}

\section{Pragmatics and Law}

\section{Practical and Theoretical Perspectives}

\section{Francesca Poggi and Alessandro Capone}

(c) Springer International Publishing Switzerland 2017

F. Poggi, A. Capone (eds.), Pragmatics and Law, Perspectives in Pragmatics, Philosophy \& Psychology 10, DOI 10.1007/978-3-319-44601-1

\section{DOI 10.1007/978-3-319-44601-1_18}

In chapter 1 titled "Slippery Meaning and Accountability", the text font and punctuation is updated.

In chapter 3 titled "What Inferentialism Tells Us About Combinatory Vagueness in Law", text has been deleted.

In chapter 11 titled "Disputable Means: Pragmatic Knowledge Practices in Sovereign Debt Agreements. Reflections on the Argentinian Case", the text font and punctuation is updated.

In chapter 12 titled "The Role of Pragmatics in the Web of Data", corrections are made in text throughout the chapter.

In chapter 13 titled "Pragmatics of Adjudication. In the Footsteps of Alf Ross", punctuation is updated throughout in the text.

In chapter 16 titled "Epistemic Stance in Courtroom Interaction", font size updated throughout the text. 